Journal of Engineering and Applied Sciences 14 (Special Issue 8): 10234-10239, 2019

ISSN: 1816-949X

(C) Medwell Journals, 2019

\title{
Measuring the Level of Radioactivity in Local and Imported used Animal Feeds in Local Markets
}

\author{
${ }^{1}$ Nadia Abdul-Hadi Abdul-Ameer, ${ }^{2}$ Shaymaa A. Kadhim Alshebly, \\ ${ }^{3}$ Zahra Mousa Hamza and ${ }^{4}$ Allawi Hamead Harjan \\ ${ }^{1}$ Department of Animal Production, Kufa Technical Institute, \\ AL Furat Al Awssat Technical University, Najaf, Iraq \\ ${ }^{2}$ Department of Physics, College of Science, University of Kufa, Kufa, Iraq \\ ${ }^{3}$ Department of Nursing, Kufa Technical Institute, \\ AL Furat Al Awssat Technical University, Najaf, Iraq \\ ${ }^{4}$ Department of Environment, College of Science, University of Kufa, Kufa, Iraq
}

\begin{abstract}
Abstruct: In this study of radioactive levels for animal feed which are negotiable Iraqi's markets .The No. of collected samples are twelve from different types and originating, the measured spectrum are made by using $\mathrm{NaI}$ (TI) detection which has dimensions " $3 * 3$ " crystal. From the spectrum results were the specific activity about from (3.0501 \pm 2.723$)$ - (9.803 \pm 2.832$)$, the range $(4.8802 \pm 2.75341) \mathrm{Bq} \mathrm{kg}^{-1}$ for ${ }^{238} \mathrm{U}$ while the specific activity about from $(0.527 \pm 0.583)-(1.583 \pm 0.611)$, the range $(0.9532 \pm 0.58695)$ for ${ }^{232} \mathrm{Th}$, the activity concentration for ${ }^{40} \mathrm{~K}$ about from $(172.5 \pm 16.47)-(80.463 \pm 9.583)$. Then, $\mathrm{R}_{\text {eq }}$ was calculated, it was about $10.488-18.486 \mathrm{~Bq} \mathrm{~kg}^{-1}$, the internal Hazard index was calculated $\left(\mathrm{H}_{\mathrm{in}}\right)$ which was about $0.0387-0.0767$ while external Hazard index $\left(\mathrm{H}_{\mathrm{ex}}\right)$ was about 0.0304-0.04052.
\end{abstract}

$\underline{\text { Key words: Radioactivity, specific activity concentration, hazards, radium equivalent, spectrum, animal feed }}$

\section{INTRODUCTION}

The radioactive activity of humans is transmitted through, vegetables and fruits as well as by the meat of animals that feed on plants $\mathrm{w}$ and while fodder. Serious radioactive substances in meat and milk appear in these animals which feed on radiation-contaminated feedings. The study of radioactive decay and nuclear reactions is a study of the dynamics of the nucleus, i.e., a properties that change with time (Zu-Jun et al., 2017). The processes of decomposition can be spontaneous (radioactive decay) or artificial (nuclear reactions). The nucleus that radiates the parent nucleus is called the nucleus of the nucleus and if the nucleus is not stable in view of the close relationship between human life and around it as there is a chain of interconnected human, animal, plant and the universe while in general, so, Artiana study the proportion of radioactivity in animal feed because of its close relationship with humans (Loveland et al., 2017). The natural radiological activity found in animal feed and the environmental radiation activity and its associated external exposure through gamma radiation depends mainly on the components of the feed and its while origin and the soil in which the plants were formed the source of the feed. External exposure means that the exposure is outside the body any product of the nuclides. The natural environment is present but the internal exposure is that which is inside the body and enters the body through nutrition and breathing (Tzortzis et al., 2004).

\section{MATERIALS AND METHODS}

Collection of samples: Various samples were selected from the components of the plant feed and the various imported and local food additives used in the manufacture of poultry and large livestock diets. Twelve samples were collected from while local markets (Huang et al., 2017).

Sample Preparation: The materials were exposed to direct sunlight for $10 \mathrm{~h}$ and purified from impurities, dried in the convection oven at 600 for $24 \mathrm{~h}$. Take $500 \mathrm{~g}$ of each sample and put in Marnelli baker (Pan et al., 2012).

Efficiency Calibration: Efficient detector (e) is known as the a proportion between the number of photons of the gamma falling on it and the number of pulses out of it which are always $<100 \%$ and are necessary for accuracy as in flowing Eq. 1 (Makki et al., 2014) (Fig. 1).

$$
\varepsilon=\frac{\mathrm{C}}{\mathrm{A} \cdot \gamma \cdot \mathrm{t}} \times 100 \%
$$

The effectiveness of a known source is used to correct by using the following relation (Hussain et al., 2010). 


$$
\mathrm{A}=\mathrm{A}_{0} \mathrm{e}^{-\lambda \Delta t}
$$

Where:

A : The Activity $(\mathrm{Bq})$ of the source at time $\mathrm{t}$

$A_{\circ}$ : The initial Activity $(B q)$ of each source at time $t_{\circ}$

$\lambda$ : The decay constant and $\left(\Delta \mathrm{t}=\mathrm{t}-\mathrm{t}_{\mathrm{o}}\right)$

Radiation background: All measurement systems record the radiation background signals due to natural radiation

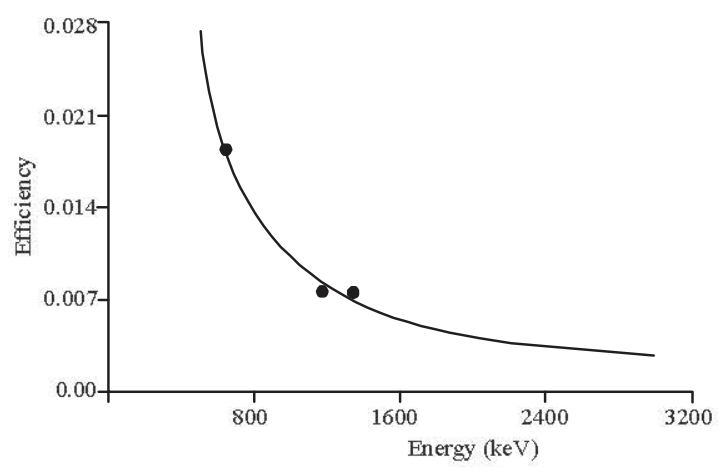

Fig. 1: The efficiency calibration curve of $3 \times 3 \mathrm{NaI}$ (T1) detector activity in the ground materials, cosmic rays and structural materials in the system and building materials surrounding the system. This background varies from one place to another and depends on the quality and size of the detector and also depends on the quality of the shield used and can increase this background because of radiation interaction. For the purpose of measuring pure radiological activity in the studied models, a spectrum of the radiological background must be recorded and subtracted from the spectrum of each model. Figure 2 shows the background radiation spectrum of the gamma ray. The irradiation background was measured by placing a $1 \mathrm{~L}$ empty marnelly vessel used for collecting study samples for a period of $18,000 \mathrm{sec}$. And collecting the spectrum on the calculator screen and subtracting it from the spectrum of the studied models (Hussain, 2011).

Sample spectrum after collecting and configuring the models and calibrating the detection and measurement system and recording the spectrum of the radiation background, the spectral spectrum was recorded for the studied models where the measurement time was second. About 18000 blocks were $0.5 \mathrm{~kg}$ models (Anderson and Hough, 1984) (Fig. 3).

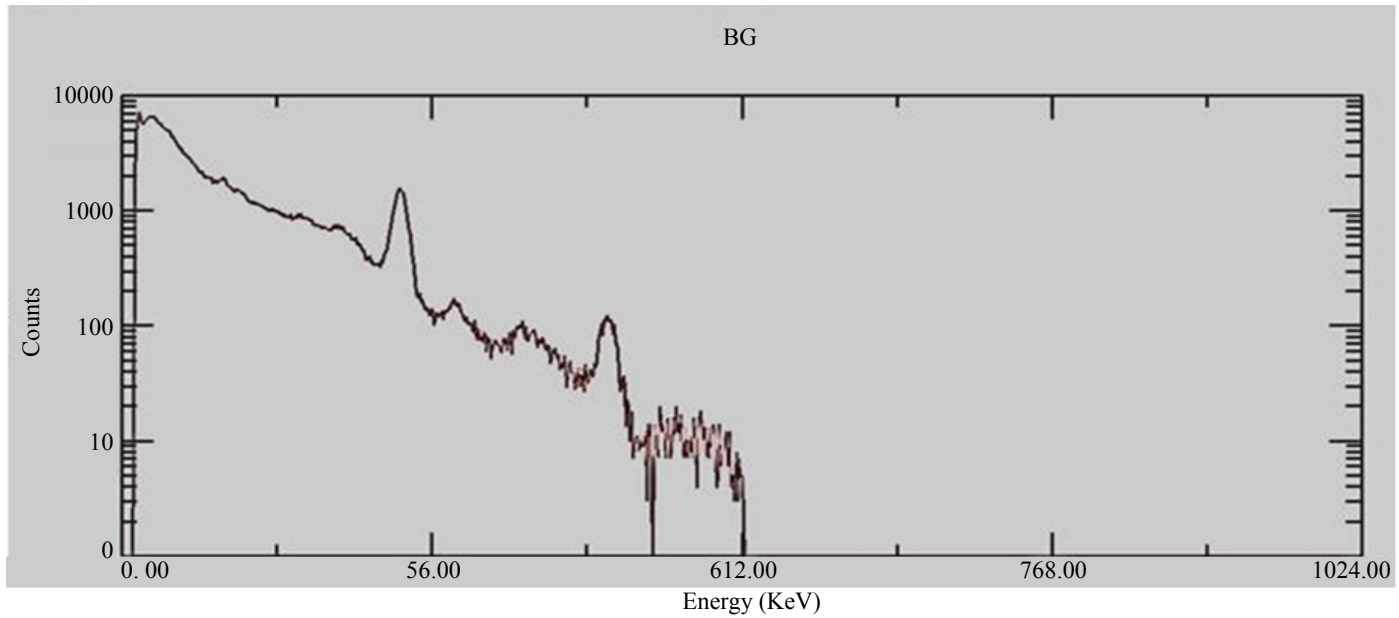

Fig. 2: Background spectra of the gamma ray
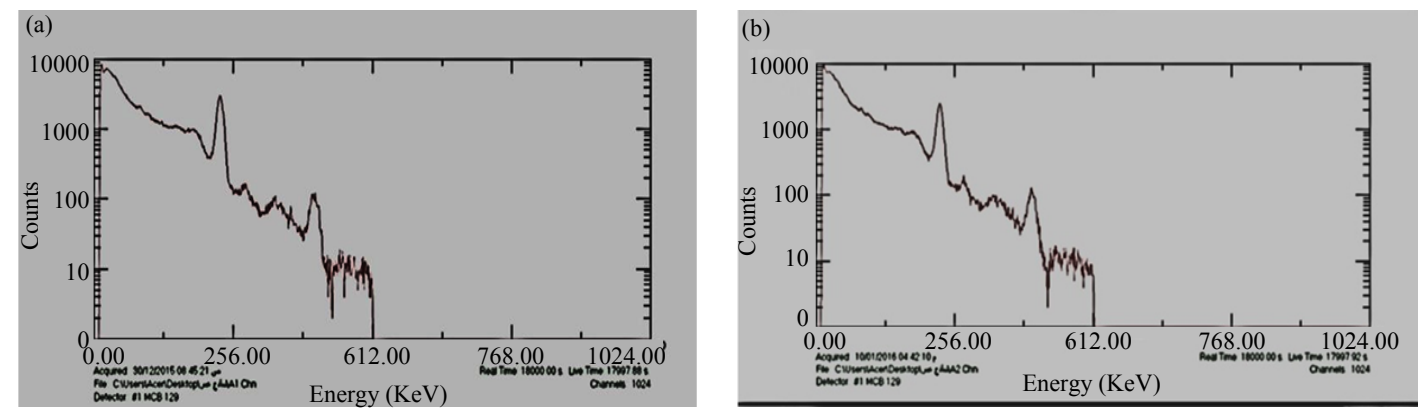

Fig. 3: Continue 
J. Eng. Applied Sci., 14 (Special Issue 8): 10234-10239, 2019
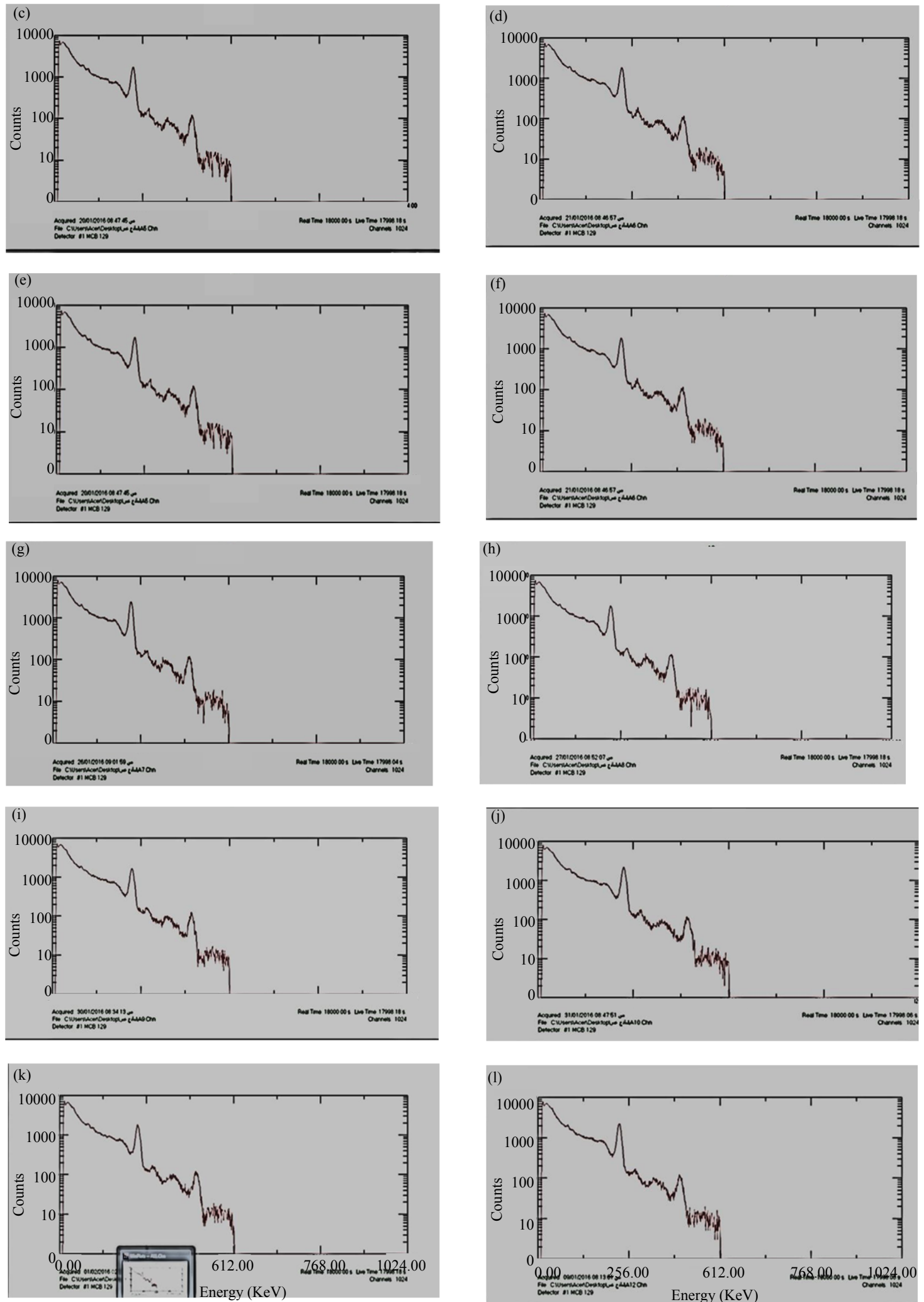

Fig. 3(a-1): Spectral radiation spectrum for studied feed models (A1-A12) between energy (MeV) in $\mathrm{x}$-axis and the counts on the y-axis: (a) A1, (b) A2, (c) A3, (d) A4, (e) A5, (f) A6, (g) A7, (h) A8, (i) A9, (j) A10, (k) A11 and (1) A12 


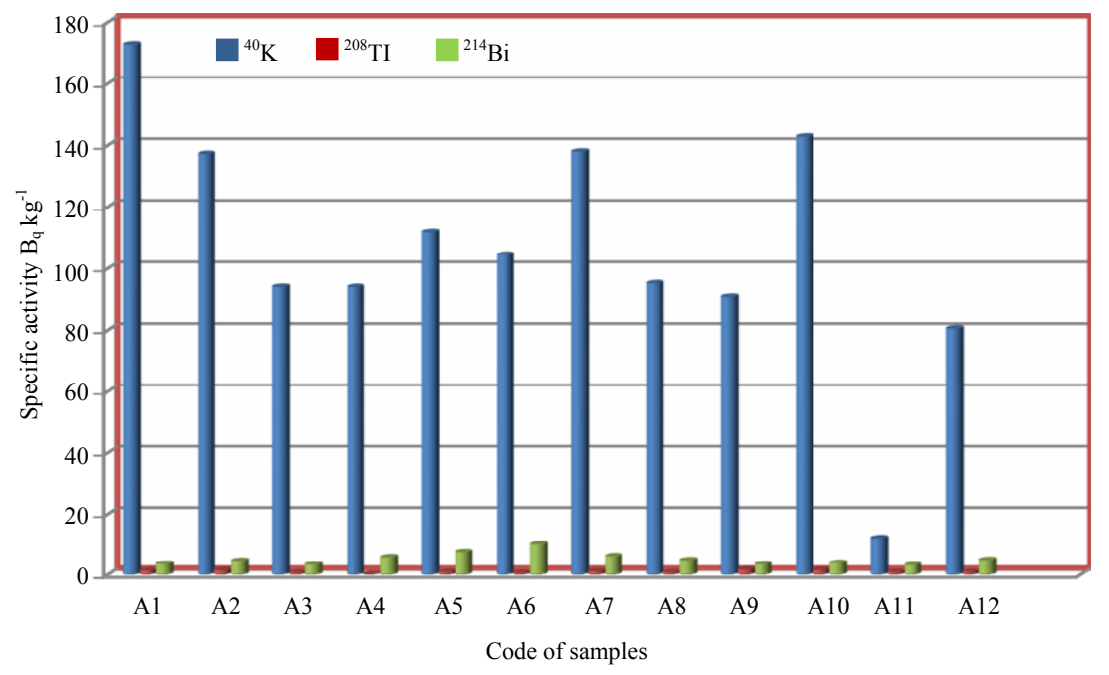

Fig.4: Specific effectiveness of the studied models in local and imported used animal feeds in local markets

\section{RESULTS AND DISCUSSION}

The activity of ${ }^{238} \mathrm{U}$ is guessed from the $1765 \mathrm{keV}$ gamma transition energy of ${ }^{214} \mathrm{Bi}(15.96 \%$ possibility). Activity of ${ }^{232} \mathrm{Th}$ was calculated from the $2614 \mathrm{keV}$ gamma transition energy of ${ }^{208} \mathrm{Tl}$, (99\% possibility) whereas ${ }^{40} \mathrm{~K}$ activity is calculated by using the $1460 \mathrm{keV}$ gamma ray line ( $11 \%$ possibility). The specific activity is defined as activity per unit mass of radioactive substance and the reported in units such as curie per gram or becquerel per kilogram. To while calculate specific activity of each radionuclide using the following Eq. 3 (Makki et al., 2014):

$$
\mathrm{A}\left(\mathrm{Bq} \mathrm{kg}^{-1}\right)=\frac{\mathrm{C}}{\varepsilon \cdot \gamma \cdot \mathrm{m} \cdot \mathrm{t}}
$$

Where:

C : Net peak count (background subtracted

A : The specific activity of the radionuclide in $\mathrm{Bq} \mathrm{kg}^{-1}$

$\varepsilon$ : The counting efficiency

$\gamma$ : The percentage of gamma emission probability of the radionuclide under study)

$\mathrm{t}$ : The counting time ( $\mathrm{sec}$ )

$\mathrm{m}$ : The mass of the sample (kg) (Hussain et al., 2010)

Competence was calculated at the energies of the study. Table 1 shows the nuclei used in the study and the associated energy and efficiency of each energy. From the Table 2 and Fig. 4 we observed the specific effectiveness of the studied models in local and imported used animal feeds in local markets we found the activity of ${ }^{238} \mathrm{U}$ is maximum in Brazil sample is minimal in local sample, Activity of ${ }^{232} \mathrm{Th}$ maximum in local sample while is minimal in Brazil sample and ${ }^{40} \mathrm{~K}$ activity maximum in Argentina sample is minimal in (Vitamine G) sample.

Figure 4 is represented the relation between the name of the code of all samples and specific activity in local
Table 1: Nuclei used in the study, energy and efficiency

\begin{tabular}{lccc}
\hline $\mathrm{I}(\%)$ & Efficiency $(\%)$ & Energy $(\mathrm{KeV})$ & Nuclei \\
\hline 0.1060 & 0.007 & 1460 & ${ }^{40} \mathrm{~K}$ \\
0.1700 & 0.006 & 1764 & ${ }^{214} \mathrm{Bi}$ \\
1.0000 & 0.004 & 2614 & ${ }^{208} \mathrm{Tl}$ \\
\hline
\end{tabular}

and imported used animal feeds in local markets. Hazard measurements depending on the specific efficiency of ${ }^{214} \mathrm{Bi},{ }^{208} \mathrm{Th}$ and ${ }^{40} \mathrm{~K}$, several risk factors were measured.

External Hazard index $\left(\mathrm{H}_{\mathrm{ex}}\right)$ : The external risk guide is an assessment of the natural gamma radiation risk, calculated from the following Eq. 5 (Brown et al., 2008):

$$
\mathrm{H}_{\mathrm{ex}}=\frac{\mathrm{A}_{\mathrm{U}}}{370}+\frac{\mathrm{A}_{\mathrm{TH}}}{259}+\frac{\mathrm{A}_{\mathrm{K}}}{4810} \leq 1
$$

This factor should be less than one. If it is equal to or greater than one, it indicates a radiation hazard.

Internal Hazard index $\left(\mathrm{H}_{\text {in }}\right)$ : The internal exposure is the result of the inhalation of radon and its fluids which can be expressed in terms of internal risk factor and calculated by the following Eq. 6 (Beir, 1990):

$$
\mathrm{H}_{\text {in }}=\frac{\mathrm{A}_{\mathrm{U}}}{185}+\frac{\mathrm{A}_{\mathrm{TH}}}{259}+\frac{\mathrm{A}_{\mathrm{K}}}{4810} \leq 1
$$

This factor should be less than one per cent to be within the internationally permissible. From Table 3 and Fig. 5, we noted the hazard-index (insider) is maximum in Holland (A2) (sample while is minimal in local (A3) sample where hazard-index (external) is maximum in local (A5) sample while is minimal in local (A3) sample. 
Table 2: The specific effectiveness of the studied models

\begin{tabular}{|c|c|c|c|c|}
\hline \multirow[b]{2}{*}{ Sample name } & \multirow[b]{2}{*}{ Country } & \multicolumn{3}{|c|}{ Specific activity $\mathrm{Bq} \mathrm{kg}^{-1}$} \\
\hline & & ${ }^{214} \mathrm{Bi}$ & ${ }^{208} \mathrm{Tl}$ & ${ }^{40} \mathrm{~K}$ \\
\hline $\mathrm{A} 1$ & Argentina & $3.376 \pm 2.838$ & $1.25 \pm 0.5833$ & $172.5 \pm 16.471\{\max \}$ \\
\hline A2 & Holland & $4.357 \pm 2.941$ & $1.361 \pm 0.611$ & $137.166 \pm 14.974$ \\
\hline $\mathrm{A} 3$ & Local & $3.159 \pm 2.832$ & $0.611 \pm 0.611$ & $94.048 \pm 12.578$ \\
\hline A4 & Local & $5.555 \pm 2.838$ & $0.6+94 \pm 0.583$ & $94.040 \pm 12.728$ \\
\hline A5 & Local & $7.189 \pm 2.838$ & $0.777 \pm 0.583$ & $111.710 \pm 12.728$ \\
\hline A6 & Brazil & $9.803 \pm 2.838\{\max \}$ & $0.527 \pm 0.583\{\min \}$ & $104.372 \pm 13.027$ \\
\hline A7 & Local & $5.882 \pm 2.838$ & $1 \pm 0.583$ & $173.915 \pm 14.974$ \\
\hline A8 & Local & $4.575 \pm 2.838$ & $0.638 \pm 0.583$ & $95.238 \pm 12.878$ \\
\hline A9 & Local & $3.267 \pm 2.838$ & $1.538 \pm 0.611\{\max \}$ & $90.895 \pm 12.578$ \\
\hline $\mathrm{A} 10$ & Center most Euphraties & $3.703 \pm 2.838$ & $1.444 \pm 0.583$ & $142.707 \pm 14.225$ \\
\hline A11 & Local & $3.0501 \pm 2.723\{\min \}$ & $0.777 \pm 0.722$ & $119.796 \pm 12.878$ \\
\hline $\mathrm{A} 12$ & Vitamine $\mathrm{G}$ & $4.647 \pm 1.888$ & $0.777 \pm 0.4074$ & $80.463 \pm 9.583 \mathrm{~min}$ \\
\hline
\end{tabular}

Table 3: External and internal risk factors of the models taken

\begin{tabular}{|c|c|c|c|}
\hline \multirow{2}{*}{$\begin{array}{l}\text { Sample } \\
\text { name }\end{array}$} & \multirow[b]{2}{*}{ Country } & \multicolumn{2}{|c|}{ Hazard-index } \\
\hline & & Insider & External \\
\hline $\mathrm{A} 1$ & Argentina & 0.0588 & 0.04947 \\
\hline A2 & Holland & 0.572 & 0.04540 \\
\hline $\mathrm{A} 3$ & Local & 0.0387 & 0.0304 \\
\hline A4 & Local & 0.522 & 0.372 \\
\hline A5 & Local & 0.06507 & 0.4564 \\
\hline A6 & Brazil & 0.0767 & 0.0502 \\
\hline A7 & Local & 0.0641 & 0.0483 \\
\hline A8 & Local & 0.0447 & 0.0324 \\
\hline A9 & Local & 0.0426 & 0.0338 \\
\hline A10 & Center most Euphraties & 0.05519 & 0.04518 \\
\hline A11 & Local & 0.0443 & 0.0316 \\
\hline A12 & Vitamine $\mathrm{G}$ & 0.0448 & 0.04052 \\
\hline & Average & 0.0537 & 0.04052 \\
\hline
\end{tabular}

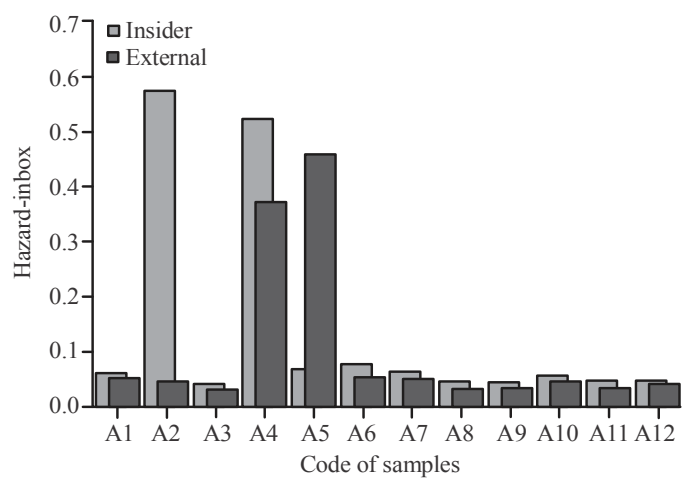

Fig.5: External and internal risk factors of the studied models in local and imported used animal feeds in local markets

Radium equivalent activity $\left(\mathbf{R a}_{\mathrm{eq}}\right)$ : In order to represent or evaluate the radiological hazards associated with the three different radiations of ${ }^{238} \mathrm{U}{ }^{232} \mathrm{Th}$ and ${ }^{40} \mathrm{~K}$ a single quantity a common while operator called radium equivalent activity $\left(\mathrm{Ra}_{e q}\right)$ is calculated. It is mathematically defined by the equation below (Santawamaitre et al., 2014):

$$
\mathrm{Ra}_{\text {eq }} \mathrm{Bq} \mathrm{kg}^{-1}=\mathrm{A}_{\mathrm{U}}+1.43 \mathrm{~A}_{\mathrm{Th}}+0.077 \mathrm{~A}_{\mathrm{K}}
$$

where, $A_{U}, A_{T h}$ and $A_{K}$ are the specific activities of uranium. Thorium and potassium, respectively
Table 4: Radium equivalent in the studied models

\begin{tabular}{lccr}
\hline $\mathrm{Ra}_{\mathrm{eq}} \mathrm{Bq} / \mathrm{Kg}^{-1}$ & $\mathrm{~A}_{214 \mathrm{Bi}}$ & $\mathrm{A}_{208 \mathrm{Th}}$ & \multicolumn{1}{c}{$\mathrm{A}_{40 \mathrm{~K}}$} \\
\hline $\mathbf{1 8 . 4 8 8}$ & 3.3760 & 1.250 & 172.5000 \\
16.865 & 4.3570 & 1.361 & 137.1660 \\
$\mathbf{1 0 . 4 8 8}$ & 3.1590 & 1.611 & 94.0480 \\
13.813 & 5.5550 & 0.964 & 94.0401 \\
16.901 & 7.1890 & 0.777 & 111.7100 \\
17.915 & 9.8030 & 0.527 & 104.3720 \\
12.820 & 5.8820 & 0.583 & 137.9150 \\
12.529 & 4.5750 & 0.638 & 95.2380 \\
16.756 & 3.2670 & 1.583 & 90.8950 \\
13.385 & 3.7030 & 1.444 & 142.7070 \\
17.930 & 3.0501 & 0.777 & 119.7960 \\
11.935 & 4.6470 & 0.777 & 80.4630 \\
$\mathbf{1 4 . 9 8 4}$ & Average & - & - \\
\hline
\end{tabular}

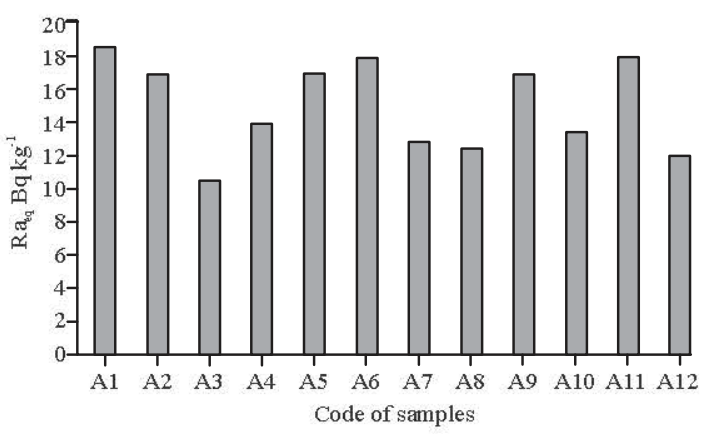

Fig. 6: Radium equivalent of the studied models in local and imported used animal feeds in local markets

(Brown et al., 2008). From Table 4 and Fig. 6, we computed the Radium equivalent where was maximum in $\mathrm{A} 1$ is minimal in $\mathrm{A} 3$ sample.

\section{CONCLUSION}

The specific activity of ${ }^{238} \mathrm{U},{ }^{232} \mathrm{Th}$ and ${ }^{40} \mathrm{~K}$ was $-0.611 \pm 1.583 " 2.273 \pm 3.0501-2.83 \pm 9.803$ calculated $172.5 \pm 16.471-80.463 \pm 9.583$ ", respectively and these " $0.583 \pm 0.527$ concentrations were within the internationally permissible limits. The radium equivalent was calculated as the range between 10.488-18.488 $\mathrm{Bq} \mathrm{kg}{ }^{-1}$ and the rate was $14.984 \mathrm{~Bq} \mathrm{~kg}^{-1}$ also among the internationally allowed. The internal risk factor was calculated from $0.0387-0.767$ and the rate was 0.0537 . 
The external risk factor was calculated from $0.0502-0.0302$ and the rate was 0.04052 . The results were within the limits allowed while internationally.

\section{ACKNOWLEDGEMENTS}

We would like to thank Dr. Fouad A. Majeed/University of Babylon/College of Education for pure Sciences/Department of Physics.

\section{REFERENCES}

Anderson, J.G. and S.E. Hough, 1984. A model for the shape of the fourier amplitude spectrum of acceleration at high frequencies.Bull. Seismol. Soc. Am., 74: 1969-1993.

Beir, V., 1990. Health Effects of Exposure to Low Levels of Ionizing Radiation. National Academy Press, Washington, DC., Pages: 421.

Brown, J.E., B. Alfonso, R. Avila, N.A. Beresford and D. Copplestone et al., 2008. The ERICA tool. J. Environ. Radioact., 99: 1371-1383.

Huang, H.W., S.J. Wu, J.K. Lu, Y.T. Shyu and C.Y. Wang, 2017. Current status and future trends of high-pressure processing in food industry. Food Control, 72: 1-8.

Hussain, H.H., R.O. Hussain, R.M. Yousef and Q. Shamkhi, 2010. Natural radioactivity of some local building materials in the middle Euphrates of Iraq. J. Radioanal. Nucl. Chem., 284: 43-47.Hussain, R.O. and H.H.
Hussain, 2011. Investigation the natural radioactivity in local and imported chemical fertilizers. Braz. Arch. Biol. Technol., 54: 777-782.

Loveland, W.D., D.J. Morrissey and G.T. Seaborg, 2017. Modern Nuclear Chemistry. 2nd Edn., Wiley Publishing Company, Hoboken, New Jersey, USA., ISBN:9781119328483, Pages: 752.

Makki, N.F., S.A. Kadhim, A.H. Alasadi and B.A. Almayahi, 2014. Natural radioactivity measurements in different regions in Najaf city, Iraq. Int. J. Comput. Trends Technol., 9: 286-289.

Pan, Z., Y.Y. Lu and F. Liu, 2012. Sunlight-activated long-persistent luminescence in the near-infrared from $\mathrm{Cr}^{3+}$-doped zinc gallogermanates. Nat. Mater., 11: $58-63$.

Santawamaitre, T., D. Malain, H.A. Al-Sulaiti, D.A. Bradley and M.C. Matthews et al., 2014. Determination of $238 \mathrm{U}, 232 \mathrm{Th}$ and $40 \mathrm{~K}$ activity concentrations in riverbank soil along the Chao Phraya river basin in Thailand. J. Environ. Radioact., 138: 80-86.

Tzortzis, M., E. Svoukis and H. Tsertos, 2004. A comprehensive study of natural gamma radioactivity levels and associated dose rate from surface soil in cyprus. Radiation Prot. Dosimetry, 109: 217-224.

Zu-Jun, Z., Z. Tian-Tian, Z. Xiao-Qing, P. Jun-Wei and L. Fei-Fei, 2017. Non-point source pollutants loss of planting industry in the Yunnan Plateau Lake Basin, China. J. Agric. Resour. Environ., 35: 40-47. 